\title{
A novel, activin-inducible, blastopore lip-specific gene of Xenopus laevis contains a fork head DNA-binding domain
}

\author{
Marie Luise Dirksen and Milan Jamrich ${ }^{1}$ \\ Laboratory of Molecular Pharmacology, Division of Biochemistry and Biophysics, Center for Biologics Evaluation \\ and Research, Food and Drug Administration, Bethesda, Maryland 20892 USA
}

The organizer region, or dorsal blastopore lip, plays a central role in the initiation of gastrulation and the formation of the body axis during Xenopus development. A similar process can also be induced in ectodermal explants by activin or by injection of activin mRNA into embryos. We have searched early embryo-specific cDNA libraries for genes containing the fork head box sequence that encodes a DNA-binding domain similar to that of the Drosophila homeotic gene fork head and rat hepatocyte nuclear factor HFN $3 \beta$. These genes were subsequently tested for expression in the organizer region of blastula/gastrula-stage embryos as well as inducibility by activin. Our effort resulted in the isolation of a gene, $X F K H 1$, that is primarily expressed in the dorsal blastopore lip of early gastrulae and is inducible by activin. At later stages it is expressed in the notochord and neural floor plate. Because of its spatial and temporal expression pattern, as well as its inducibility by activin, this gene is a good candidate to have a regulatory function in the initial processes of axis formation in Xenopus laevis embryos.

[Key Words: Activin; fork head domain; mesodermal induction; neural floor plate; neural induction; notochord]

Received December 16, 1991; revised version accepted February 19, 1992.

The molecular analysis of developmental biology, especially pattern formation, has experienced major growth during the last decade. This is primarily the result of the discovery that many of the genes controlling pattern formation are members of multigene families. They encode conserved DNA-binding domains such as the homeo domain (for review, see Scott et al. 1989; Wright et al. 1989), paired domain (Bopp et al. 1986; Walter et al. 1991), or POU domain (Herr et al. 1988; Kessel and Gruss 1990; Rosenfeld 1991). This fact has been utilized to isolate additional gene family members in a variety of species, including flies, frogs, worms, and man. In Drosophila, individual family members are expressed throughout the entire period of embryonic development in consecutive, spatially restricted waves that comprise a regulatory cascade. Consequently, genes expressed early in development are likely to be crucial in the initiation of the pattern-forming chain of events. In Xenopus, zygotic transcription starts $7 \mathrm{hr}$ after fertilization following a period of transcriptional silence (Bachvarova and Davidson 1966; Newport and Kirschner 1982). This is also the time period during which cell type-specific transcrip-

${ }^{1}$ Corresponding author. tion begins (Jamrich et al. 1987). Therefore, if any zygotic gene has a role in the initiation of pattern formation it would have to be expressed at this stage of development. This period of embryogenesis (blastula/carly gastrula) also coincides with the beginning of mesodermal and neural induction. A search for factors involved in mesodermal induction has led to the discovery that peptide growth factors such as basic fibroblast growth factor (bFGF) and transforming growth factor $\beta$ (TGF- $\beta$ ) can promote mesoderm formation in ectodermal explants (Kimelman and Kirschner 1987; Slack et al. 1987; Smith 1989; Roberts et al. 1990). It was found that activin, a growth factor related to TGF- $\beta$, is not only able to induce mesoderm formation but can also induce axis formation in uncommitted ectodermal explants (Asashima et al. 1990; Smith et al. 1990; Sokol et al. 1990). The resulting tissue frequently resembles a mini-embryo. Furthermore, microinjection of activin mRNA into embryos can also induce secondary axis formation (Thomsen et al. 1990|, indicating that activin is somehow able to activate the correct pattern-forming chain of events. One would therefore expect that genes involved in the initiation of pattern formation would display a rapid activation response to mesoderm-inducing factors, especially activin. When morphologically visible pattern formation 
begins, a region of the embryo termed the blastopore lip or the "organizer" plays a critical role (Nieuwkopp 1973). Although the steps leading to the determination of the dorsoventral axis begin at fertilization (Elinson and Kao 1989; Gerhart et al. 1989), the formation of the dorsal blastopore lip is the first morphological demonstration that the dorsoventral axis has been established. Mesodermal cells originating in this region migrate toward the animal pole of the embryo, inducing the overlying uncommitted ectodermal cells to form neural tissue. The dorsal blastopore lip has the extraordinary ability to induce a secondary axis when transplanted to another embryo (Spemann and Mangold 1924). One might therefore expect that a gene involved in the initial pattern-forming events would be expressed in this area of early gastrulae. For these reasons we have searched for genes that are expressed at the beginning of zygotic transcription in the dorsal marginal region and are at the same time inducible by activin. It has been found previously that some homeo box-containing genes respond to mesoderm inducers. The gene Mix 1 shows a quick response to activin induction (Rosa 1989). It is, however, expressed in the entire endodermal region of the embryo, and it is not clear whether this gene is involved in axis formation. Two other homeo box-containing genes that respond to mesodermal inducers are thought to be involved in the later, posterior development of the embryo (Ruiz i Altaba and Melton 1989; Cho and De Robertis 1990; Cho et al. 1990).

Whereas several previous efforts have concentrated on homeo box-containing genes, we have screened early embryo-specific libraries for genes encoding the fork head $(f k h)$ domain. This DNA-binding domain was originally described in the Drosophila homeotic gene $f k h$ (Weigel et al. 1989; Weigel and Jäckle 1990) and in rat hepatocyte transcription factor $H N F 3 \alpha$ (Lai et al. 1990, 1991). This 110-amino-acid domain is highly conserved between these two genes, suggesting that other species might also contain genes with this domain. In this paper we describe a Xenopus gene, $X F K H 1$, which encodes a $f k h$ domain protein. The XFKH1 gene is activated at the onset of zygotic transcription in the dorsal marginal zone of the embryo and can be induced in ectodermal explants even in the absence of protein synthesis. Its expression pattern during early development, as well as its inducibility by activin, suggests that this gene might play a pivotal role in the initiation of pattern formation in $\mathrm{Xe}$ nopus embryos.

\section{Results}

\section{Isolation and characterization of the XFKH1 gene}

Using degenerate primers and polymerase chain reaction (PCR)-based technology (Saiki et al. 1988), we have isolated a cDNA clone containing a Xenopus $f k h$ box. We have used degenerate primers corresponding to the conserved ITMAIQ and NMFENG sequences of the rat hepatocyte transcription factor $H N F 3 \alpha$ and Drosophila $f k h$ box. As a template we have used DNA prepared from a gastrula-specific cDNA library (Sargent and Dawid 1983). After amplification, a fragment of the predicted size ( $240 \mathrm{bp}$ ) was cloned, sequenced, and used to screen stage 13 and stage 24 cDNA libraries for longer cDNA clones (Richter et al. 1988). We obtained a 1.8-kb-long cDNA clone that contains the entire coding sequence of the gene and additional $5^{\prime}$ - and $3^{\prime}$-flanking sequences (Fig. 1A). We estimated from Northern blots that the entire XFKH1 RNA is $2.5 \mathrm{~kb}$ long. Therefore, we miss $\sim 700 \mathrm{bp}$, probably at the $5^{\prime}$ end. The open reading frame encodes a 400-amino-acid-long protein. It has a conserved 110 -amino-acid $f k h$ domain that is $89 \%$ identical to the hepatocyte-enriched transcription factor HNF- $3 \beta$ (Fig. 1B).

\section{Spatial and temporal localization of XFKHI $m R N A$ during embryogenesis}

As can be seen in Figure 2A, XFKH1 mRNA is not present in the oocyte. The gene is activated at, or shortly after, the midblastula transition. Considerable amounts of transcripts are present by stage 10 . The peak of expression is during gastrulation between stages 10 and 12 . After this stage, the RNA levels decline, although some transcripts are present until stage 40. Using Northern blot hybridization to RNA from eight different tissues (including brain) we did not observe any expression of this gene in adult animals. Northern blot analysis of microdissected tissues revealed that at stage 10, FKH1 RNA is primarily localized in the dorsal, vegetal region of early gastrulae, within the quadrant of the embryo containing the dorsal blastopore lip (Fig. 2B). More detailed analysis of expression was performed using in situ hybridization to whole embryos with digoxigenin-labeled RNA probes (Figs. 3-5). We found that the expression of this gene can be visualized first in late blastulae /stage $91 / 2)$. The gene is expressed in the dorsal marginal zone (Fig. 3A). The highest level of expression is in the middle of the dorsal marginal zone. This is the area where the future dorsal blastopore lip will form. During gastrulation, the highest concentration of XFKH1 RNA is in the dorsal blastopore lip (Fig. 3B-D). In the process of gastrulation, this gene is first expressed in the invaginating mesoderm, followed closely by adjacent neural tissue (Fig. 4A,B). The expression within the mesodermal tissue is limited to the chordal mesoderm (see Fig. 5A-C). No expression can be seen in the presomitic mesoderm. In the neural plate, only the prospective floor plate shows expression. As neurulation proceeds, expression extends toward the anterior region of the embryo (Fig. 4C). At the same time, the gene starts to be progressively inactivated from the posterior end of the embryo. At the end of neurulation only the expression in the anterior neural region remains (Fig. 4D); at later stages the expression weakens. No expression can be seen in isolated tadpole brains (stage 45) using whole-mount in situ hybridization. The exact anterior limit of $X F K H 1$ hybridization is not known at present. From the whole-mount in situ hybridization with a combined probe of XFKH1 and engrailed 2 (Hemmati-Brivanlou and Harland 1989) we conclude 


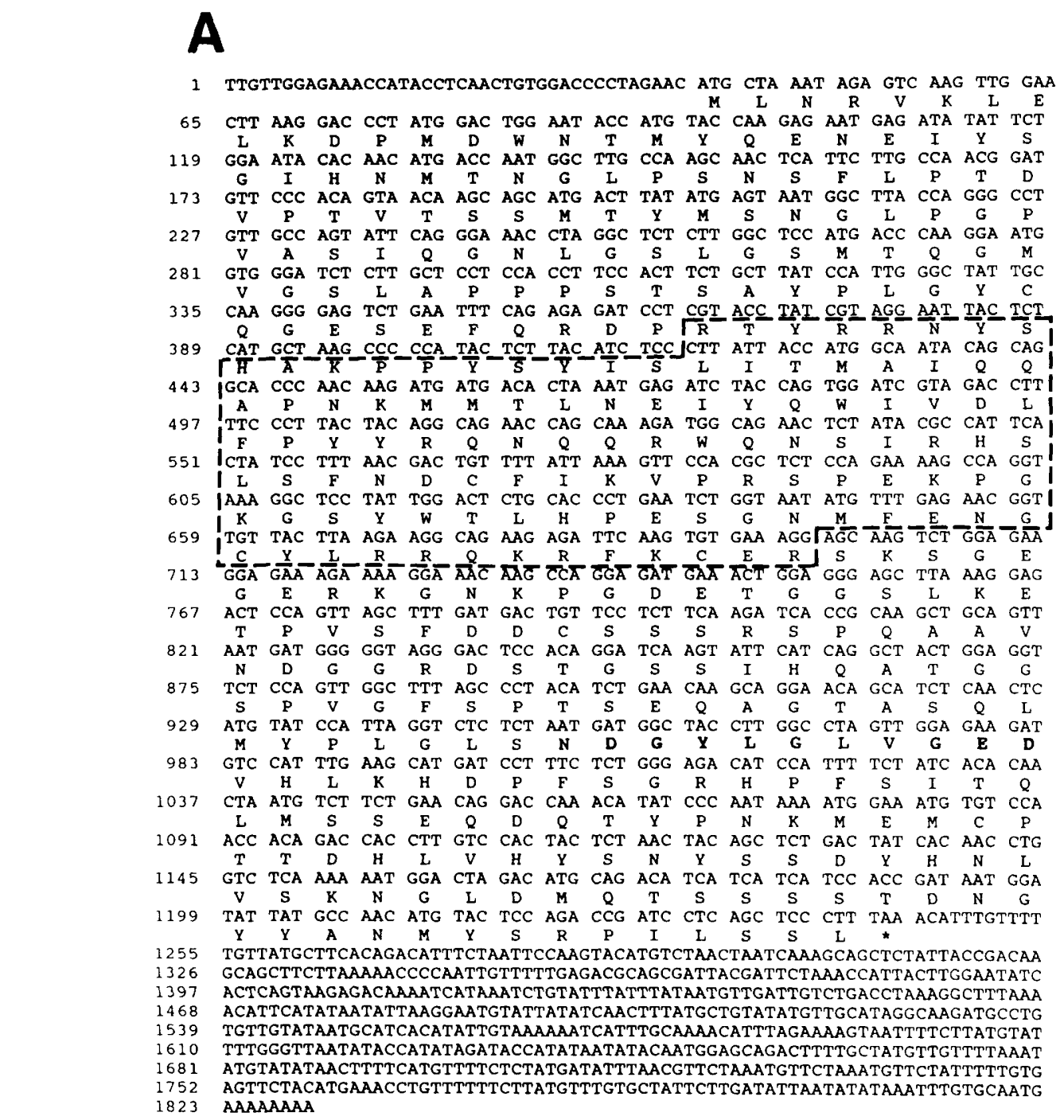

B

Figure 1. The nucleotide sequence of XFKH1 and its corresponding amino acid sequence. (A) Amino acids are in the single-letter IPAC code. The $f k h$ domain is boxed in. The termination codon is indicated by an asterisk $(*) .(B)$ Comparison of the $f k h$ domain of $X F K H 1$ to the similar domains in the rat transcription factor HNF-3 $\beta$ (Lai et al. 1991) and Drosophila homeotic gene $f k h$ (Weigel et al, 1989). Asterisks indicate identities.

that the XFKH1 expression domain extends into the midbrain. The engrailed 2 probe hybridizes to the boundary between midbrain and hindbrain, and this double hybridization (Fig. 4E) clearly shows that XFKH1 is expressed anterior to this boundary. At present, we have no conclusive evidence that $X F K H 1$ is ever expressed in the forebrain.

The relative intensity of hybridization of the notochord and neural floor plate varies, depending on the stage of the embryo and plane of the section (Fig. 5). 


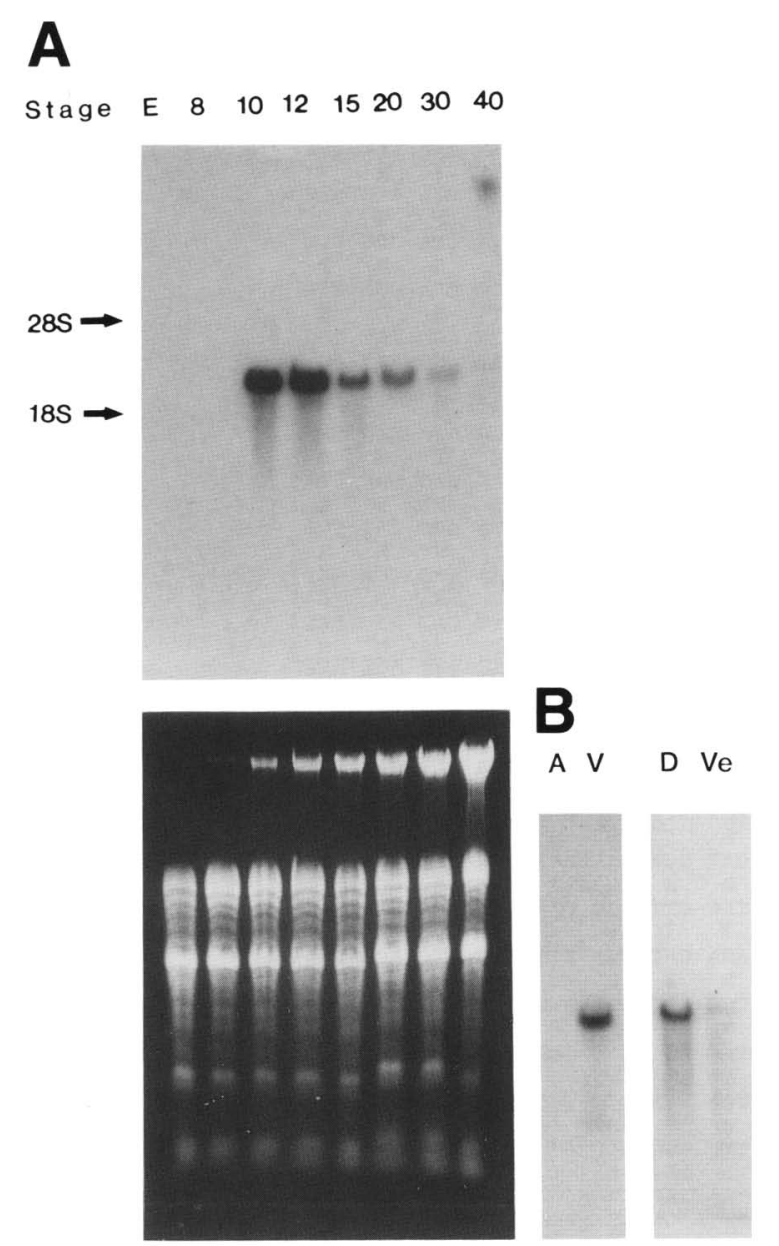

Figure 2. Developmental expression of $X F K H 1$. (A) Northern blot analysis of $10 \mu \mathrm{g}$ of total RNA from different stages of embryos. (Bottom) Ethidium bromide staining of the gel; (top) autoradiography. (Stage E) Egg; (stage 8) blastula; (stages 10,12) gastrula; (stages 15,20 ) neurula; (stages 30,40 ) tadpoles. The positions of $18 \mathrm{~S}$ and $28 \mathrm{~S}$ mRNAs are indicated by arrows. $|B|$ Northern blot analysis of RNA from dissected halves of embryos. Equal amounts of RNA $(10 \mu \mathrm{g})$ were loaded per lane. (A) Animal; (V) vegetal; (D) dorsal; (Ve) ventral.

Whereas earlier, the notochord seems to be the major site of expression (Fig. 5A), later, especially in the anterior region, the neural floor plate hybridizes best (Fig. $5 \mathrm{~B})$. The hybridization within the notochord is not uniform. There is a slight dorsoventral gradient with more intense hybridization in the dorsal region (Fig. $5 \mathrm{C}$ ).

The expression of XFKH1 in the neural floor plate suggests that this gene is expressed in this tissue as a result of induction from underlying notochord. Alternatively, the signal could be generated in the organizer region and travel within the plane of the ectoderm. In this case, the contact of ectodermal cells to the underlying mesodermal cells would not be essential for the expression of this gene. To address this question we have treated embryos with high salt buffer. This treatment induces formation of exogastrulae. In these embryos the normal contact of chordal mesoderm and ectoderm is eliminated. Wholemount in situ hybridization of complete exogastrulae shows that XFKH1 is expressed in the notochord but not in the ectoderm (Fig. 4F). This result suggests that a contact between mesoderm and ectoderm is required for the normal level of expression of this gene in the neural plate. No such contact is required for the expression of this gene in the notochord.

\section{Induction of XFKH1 by activin}

Because it has been shown that activin can induce axis formation in animal caps, we have examined the XFKH1 gene for inducibility by growth factors. As seen in Figure 6 , this gene is specifically induced by activin. Animal caps cultured in saline did not express this gene, and FGF alone was not sufficient to induce gene activity. This result agrees well with general expectations as it is known that TGF- $\beta$-like growth factors induce preferentially dorsal structures, whereas FGF-like growth factors induce mostly ventral mesoderm. In comparison, gene 1A11 (Rosa and Dawid 1990), which was used in this experiment as a control, is induced by activin and FGF. Because the $X F K H 1$ RNA appeared rapidly after activin induction, we tested whether the $X F K H 1$ gene requires protein synthesis for its induction. As seen in Figure 7, XFKH1 gene expression can be induced in animal caps even if the animal caps are preincubated in cyclohexamide, a potent inhibitor of protein synthesis. This treatment reduces the protein synthesis by $75-95 \%$ (Rosa 1989; Cho et al. 1991b). The amount of RNA is reduced but not eliminated. The partial reduction of RNA synthesis is probably due to the fact that cyclohexamide inhibits DNA replication (Cascio and Gurdon 1987) and, therefore, fewer gene templates are available for transcription. After correction for the template copies, the level of XFKH1 is higher than in uninduced caps. This overinduction is typical for many immediate early induced genes in the presence of protein synthesis inhibitor (Ringold 1979). This result indicates that activation of XFKH1 is an immediate early response to activin induction.

\section{Discussion}

Although it has been known since the beginning of the century that a transplanted blastopore lip can organize a secondary body axis in amphibian embryos (Spemann and Mangold 1924), this process is poorly understood at the molecular level. To gain a better understanding of this process, we have searched for potential regulatory genes expressed in the organizer region of Xenopus blastula/gastrula-stage embryos.

In our search, we have concentrated on a new family of DNA-binding proteins-those containing the $f k h$ DNAbinding domain. This domain was originally found in the Drosophila homeotic gene $f k h$. Later, a similar domain was found in rat hepatocyte-enriched transcription factor $H N F 3 \alpha$. The $f k h$ gene of Drosophila encodes a nuclear protein that acts in the pattern-forming pathway by 

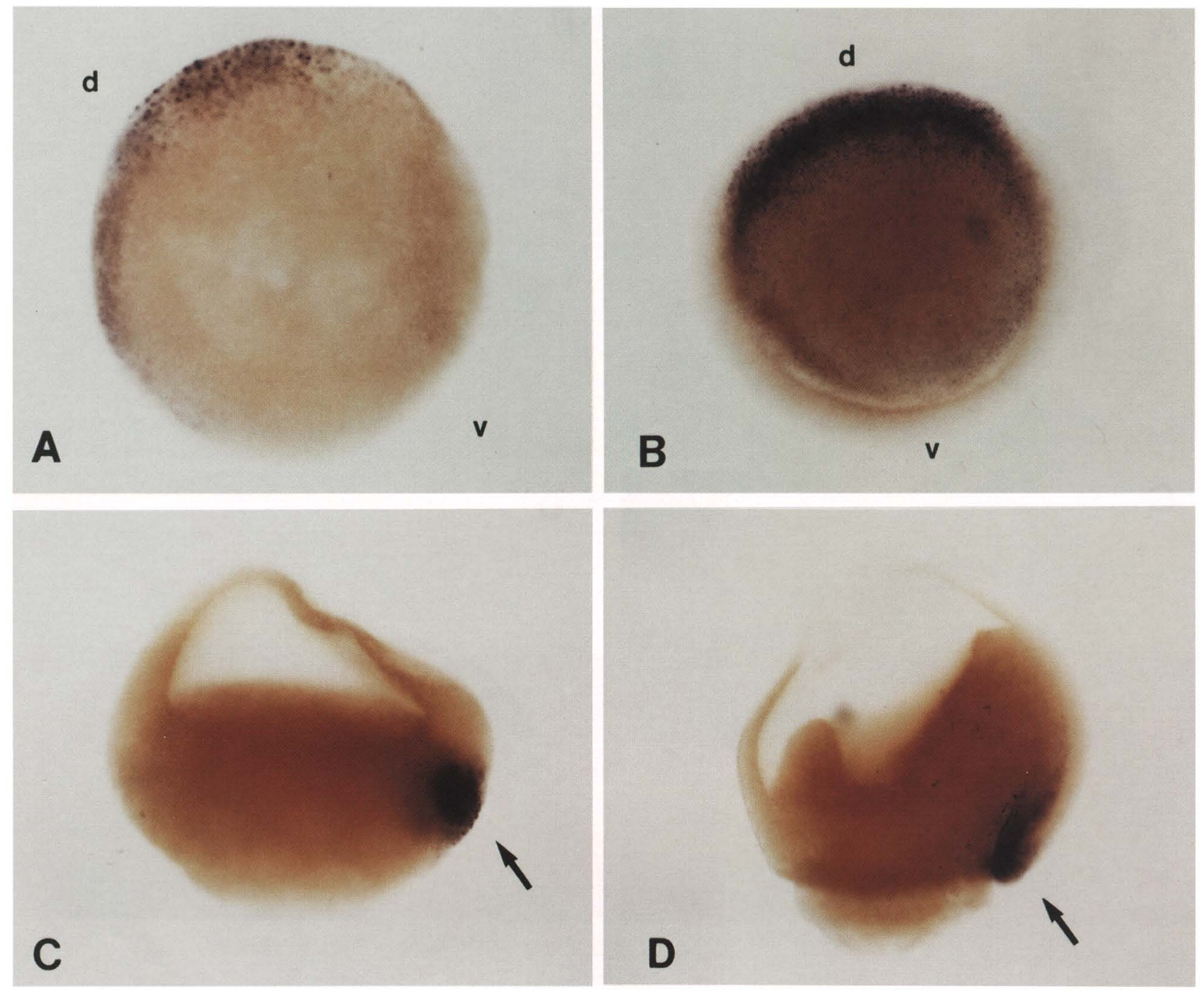

Figure 3. Whole-mount in situ hybridization analysis of $X F K H 1$ expression in Xenopus blastula and gastrula. $(A)$ In situ hybridization of XFKH1 to stage $91 / 2$ Xenopus blastula. This view from the vegetal pole of the embryo shows that the XFKH1 RNA is expressed in the dorsal marginal zone of the embryo. (d) Dorsal; (v) ventral. $(B)$ In situ hybridization of $X F K H 1$ to stage 11 Xenopus gastrula. Notice intense hybridization in the dorsal marginal zone in this vegetal view of the embryo. (d) Dorsal; $(v)$ ventral. $\{C)$ Lateral view of a stage $10^{1 / 2}$ embryo hybridized with XFKH1 cRNA. Most of the signal is in the organizer region (arrow). (D) Lateral view of stage $111 / 2$ embryo. Hybridization is primarily in the invaginating marginal zone of the dorsal blastopore lip (arrow).

influencing the development of terminal regions of the embryos. It is genetically distinct from the homeotic selector gene network that is regulated by the Polycomb group of genes. The genetic differences are paralleled by the different molecular structure of the gene (Weigel et al. 1989). The $f k h$ gene does not have a homeo box, paired box, or POU box. Instead it encodes a distinct 110-amino-acid DNA-binding domain, the $f k h$ domain.

Rat $H F N 3 \alpha$ encodes a sequence-specific DNA-binding protein that is involved in the transcriptional regulation of liver-specific genes. Two more $H N F 3 \alpha$-like genes (HNF3 $\beta, H N F 3 \gamma$ ) have been described recently (Lai et al. 1991). They all contain the highly conserved $f k h$ DNAbinding domain. We have isolated a Xenopus gene that contains a $f k h$ DNA domain. It is most similar to rat hepatocyte-enriched transcription factor $H N F 3 \beta$. By analogy, we believe that this gene is also a transcriptional regulator. Although the two genes have similarities outside the $f k h$ domain, the patterns of expression are sufficiently different, making it unlikely that these two genes are true homologs. Indeed, we have evidence that there is a family of genes in Xenopus that have similar DNA-binding motifs but distinct expression patterns.

\section{Developmental expression of XFKHI}

XFKH1 mRNA can first be detected in late blastula-stage embryos, suggesting that this gene is not transcribed in the oocyte. Using total RNA Northern blots, we can de- 

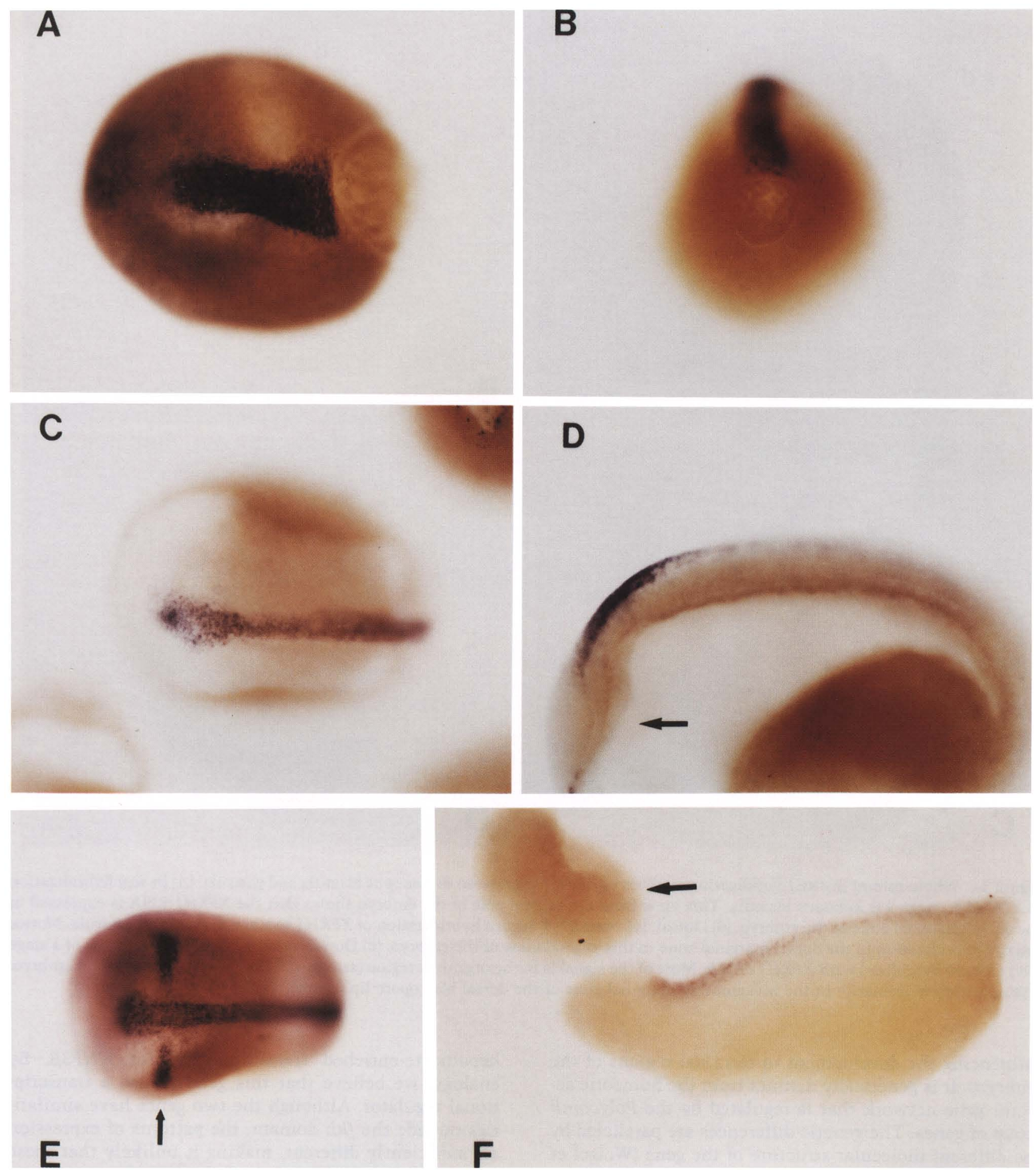

Figure 4. Whole-mount in situ hybridization of XFKH1 to Xenopus neurulae. (A) Dorsal view of stage 12 embryo showing the extent of hybridization of $X F K H 1$ in the dorsal region of the embryo. Anterior is left; posterior is right. $(B)$ Posterior view of stage $121 / 2$ embryo hybridized with XFKH1 showing the dorsal labeling of XFKH1 RNA. Hybridization is to a narrow strip of chordal mesoderm and overlying neural tissue. $(C)$ Dorsal view of stage 18 embryo showing the $X F K H 1$-labeling pattern. At this point of development, labeling extends into the brain area. $\{D \mid$ Lateral view of stage 20 embryo showing the inactivation of XFKH1 gene in the posterior region of the embryo. Forebrain area appears to be negative as well (arrow). (E) In situ hybridization of XFKH1 and engrailed 2 to a stage 18 embryo. Arrow indicates the transverse band of engrailed 2 hybridization. The hybridization resulting from the XFKH1 probe extends anteriorly beyond that of engrailed 2, which marks the boundary between midbrain and hindbrain. $(F)$ Whole-mount in situ hybridization of XFKH1 to Xenopus exogastrula. Lateral view of a Xenopus exogastrula. Hybridization signal is visible in the notochord. No signal appears in the ectoderm (arrow). The ectodermal part broke off during the examination of the embryo. 

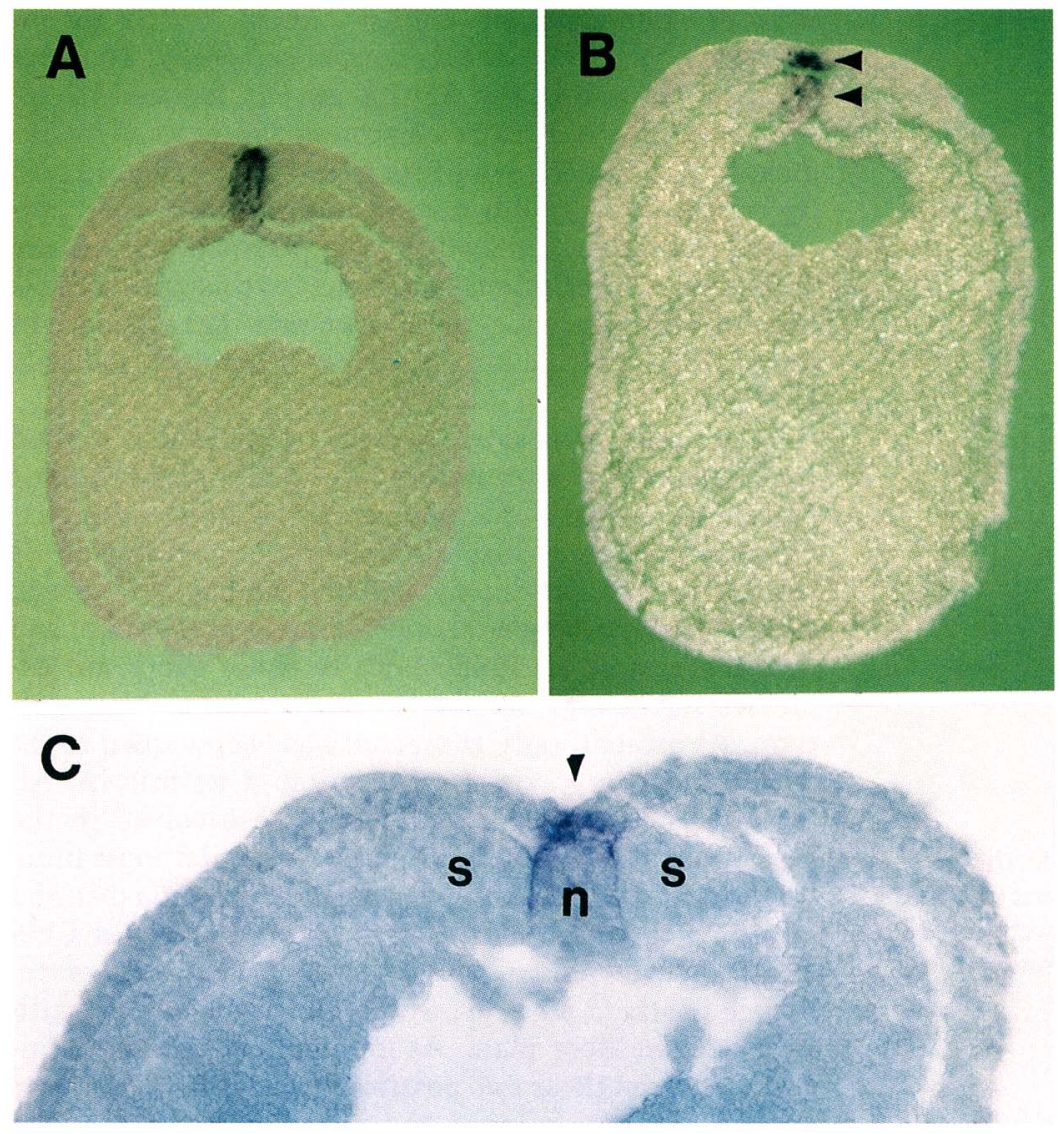

Figure 5. Sections of embryos hybridized with XFKH1. (A) Transverse section through the trunk region of a stage 15 embryo. Hybridization of $X F K H 1$ is to the notochord and putative neural floor plate. $(B)$ In situ hybridization of $X F K H 1$ to a stage 16 embryo. Section is through the hindbrain region. The upper arrow shows the hybridization in the neural floor plate; the lower arrow shows the hybridization to the notochord. This transverse section is slightly oblique. The dorsal area is more anterior than ventral. $(C)$ Higher magnification of the $X F K H 1$ hybridization to the stage 16 embryo. Hybridization is to the notochord $(\mathrm{n})$ and neural floor plate (arrow). Somites(s) and other areas of the embryo are negative. tect $X F K H 1$ RNA as early as stage 9 (data not shown). It is likely that by using more sensitive methods such as RNase protection or quantitative PCR, we would detect transcripts earlier. In late blastula, transcripts are localized in the dorsal marginal zone of the embryo, appearing

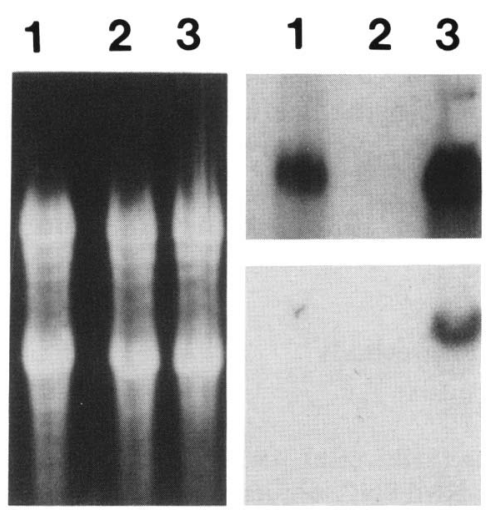

Figure 6. Effects of growth factors on the expression of $X F K H 1$. Northern blot analysis of RNA (10 $\mu \mathrm{g}$ ) from induced and uninduced animal caps. (Left) Ethidium bromide staining; (upper right) control hybridization with clone $1 \mathrm{All}$ that is known to be induced by activin and FGF; (lower right) same filter hybridized by XFKH1 (induction by activin only). (Lane 1) FGF; (lane 2) control; (lane 3) activin. before the dorsal lip is formed. Initially this gene is expressed in an arc encompassing the dorsal half of the embryo. At later stages, as the expression becomes more intense, it becomes progressively more restricted to the organizer region of the embryo. During the process of gastrulation, expression can be observed in the invaginating marginal zone. However, these transcripts are limited to chordal mesoderm. Shortly after the onset of expression in the chordal mesoderm, expression can be observed in the overlying neural plate. Expression in the neural plate is limited to what appears to be the prospective floor plate. In the process of neurulation, the expression of the XFKH1 gene extends into the brain area. At this point, we are not sure exactly how far anterior this expression extends. From the double-labeling experiments using EN2 and XFKH1 probes for in situ hybridization, it is clear that the expression extends at least into the midbrain region. We do not know whether any expression is taking place in the forebrain. At later stages, the forebrain area is largely negative; however, this might be the result of the increase in volume in the forebrain area. The pattern of XFKH1 expression, which initiates in the mesoderm followed immediately by expression in the overlying neuroectoderm, is reminiscent of Hox-2.9 gene expression in the different germ layers of early mouse embryos (Frohman et al. 1990) and suggests that the expression in the neuroectoderm is specified by 


\section{3}

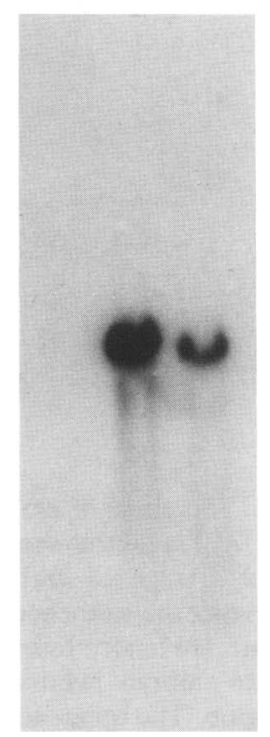

Figure 7. Northern analysis of XFKH1 induction in the presence and absence of protein synthesis. Equal amounts of RNA $(10 \mu \mathrm{g})$ from induced and uninduced animal caps were loaded per lane. (Lane 1) Control; (lane 2) activin (no cycloheximide); (lane 3) activin and cycloheximide.

the expression in the adjacent notochord. This idea of homeogenetic induction across germ layer boundaries (DeRobertis et al. 1989), in which the expression of a transcription factor in one tissue induces the expression of the same factor in the other tissue, is supported further by the experiments with exogastrulae. In these embryos, where the contact between notochord and ectoderm is experimentally eliminated, the expression of $X F K H 1$ in the notochord is unaltered but the expression corresponding to the neural floor plate is eliminated. This experiment suggests that the notochord is necessary for the formation of the neural floor plate. The lack of expression in the ectoderm of exogastrulae might be surprising in view of results of Kintner and Melton (1987) and Ruiz i Altaba (1990), who showed that neuralspecific markers $N-C A M$ and $X h o x 3$ are expressed in the exogastrula. The likely explanation for this discrepancy is that some neural-specific genes require normal contact between mesoderm and ectoderm and others do not.

\section{$\mathrm{XFKH}$ is an immediate early response to activin induction}

Peptide growth factors related to TGF- $\beta$ and bFGF can induce mesoderm formation in ectodermal animal caps. In addition, activin $\mathrm{A}$, a growth factor related to TGF- $\beta$, can also induce axis formation in these explants, mimicking the function of the organizer region of amphibian gastrula. Although it is not known whether activin is the natural inducer in vivo, activin-mediated induction can be used as a test for molecules involved in the initial steps of axis formation. We have tested XFKH1 for inducibility by activin in this animal cap assay. The data obtained show that the XFKH1 gene is induced by activin even in the absence of protein synthesis. This indicates that $X F K H 1$ is a primary response gene induced by activin-like growth factors and suggests that processes other than translation (e.g., phosphorylation) are needed for transcriptional activation of this gene. This is not entirely surprising, as it is known that the activin receptor has a serine kinase activity (Mathews and Vale 1991).

In summary, we have isolated a gene that is a good candidate to play a regulatory role in the initial steps of pattern formation in Xenopus embryos. In its initial expression pattern at blastula and gastrula, this gene is similar to two previously isolated homeo box genes, goosecoid (Blumberg et al. 1991; Cho et al. 1991a,b) and $X \lim 1$ (Taira et al. 1992). Both of these genes are expressed in the organizer region and are inducible by activin. At present, only goosecoid has been shown to induce a secondary axis after injection of its mRNA. Alternatively, the XFKH1 gene could be involved in the formation of the dorsal midline and is similar in its function to that of single-minded gene of Drosophila (Nambu et al. 1991), which acts as a marker regulator of CNS midline development and the cyclop mutation of zebrafish (Hatta et al. 1991) which, in turn, blocks specification of the floor plate. At present, we cannot distinguish between these two possibilities. Unfortunately, we cannot learn much about its function from comparison to Drosophila $\mathrm{fkh}$ expression. Drosophila $\mathrm{fkh}$ is expressed in a very different way, primarily in the most anterior and most posterior regions of the embryo. The comparison is made even more difficult by the fact that Xenopus might have as many as 10 different genes containing the $f k h$ domain $(M$. Dirksen and M. Jamrich, unpubl.). These genes seem to have vastly different expression patterns; therefore, any attempt to make a detailed comparison of XFKH1 and Drosophila $f k h$ would only be misleading. Although a specific comparison might not be useful at present, in general, it is likely that in Xenopus, as in Drosophila, some of the early functions in embryonic development are performed by homeotic selector genes such as homeo box-containing genes; others are performed by region-specific homeotic genes like $f k h$ or spalt (Frei et al. 1988; Jürgens 1988; Jürgens and Weigel 1988).

\section{Materials and methods}

\section{$P C R$ reactions}

PCR reactions (Saiki et al. 1988) with degenerate primers to ITMAIQ and NMFENG sequences were performed using the Perkin-Elmer Cetus PCR reaction kit. The reaction cycles and conditions were performed as described in Mackem and Mahon (1991).

Embryos

Developmental stages of embryos were determined according to Nieuwkoop and Faber (1967). For exogastrulation experiments, 
embryos were placed into $1 \times$ nuclear magnetic resonance at two-cell stage, and the vitelline membrane was manually removed. Exogastrulae were monitored carefully during formation, and only complete exogastrulae were selected for further analysis.

\section{Preparation of RNA}

Total RNA from embryos and tissues was prepared according to Sargent et al. (1986). Ten micrograms of RNA was loaded per lane on $1.2 \%$ agarose gels containing $5 \mathrm{~mm}$ methylmercury hydroxide (Bailey and Davidson 1976). Gels were blotted to Nytran filters using vacuum transfer. DNA probes were made using the BRL random primer labeling system with $\left[\alpha-\mathrm{P}^{32}\right] \mathrm{dCTP}$. Hybridization was performed as described by Church and Gilbert (1984).

\section{Induction experiments}

Animal caps were isolated from stage 8 blastulae. They were treated with FGF, activin, or cycloheximide according to Rosa et al. (1988) and Rosa (1989). We have used the following factor concentrations: $50 \mathrm{pm}$ activin; $100 \mathrm{ng} / \mathrm{ml}$ of bFGF.

\section{Whole-mount in situ hybridization}

In situ hybridization was performed following the method of Hemmati-Brivanlou et al. (1990) and Harland (1991). Antisense RNA probes were prepared using the Boehringer RNA labeling kit with digoxigenin-UTP. A clone containing the entire $X F K H 1$ cDNA was used as the template for transcription.

\section{Embryosections}

Embryos that gave a positive signal with whole-mount in situ hybridization were incubated $2 \mathrm{hr}$ in $100 \%$ methanol, $2 \mathrm{hr}$ in xylene, $1 \mathrm{hr}$ in $1: 1$ xylene-paraffin (Paraplast-Plus) and, finally, $6 \mathrm{hr}$ in paraplast. Incubations in paraffin were performed at $60^{\circ} \mathrm{C}$. The paraffin was solidified by transferring it to room temperature, and $30-\mu \mathrm{m}$ sections were cut and dried down on polylysine-coated slides. Paraffin was dissolved in xylene, and xylene was washed out in $100 \%$ ethyl alcohol. Sections were viewed and photographed under a coverslip in $100 \%$ alcohol.

\section{Acknowledgments}

We thank Dr. Richard Harland for introducing us to the technique of whole-mount in situ hybridization, Drs. Igor Dawid, John Green, Tom Sargent, and Klaus Richter for cDNA libraries, Dr. Kathleen Mahon for critical reading of this manuscript, Genentech, Inc., for recombinant activin A, and Ellen Caruso for the preparation of this manuscript.

The publication costs of this article were defrayed in part by payment of page charges. This article must therefore be hereby marked "advertisement" in accordance with 18 USC section 1734 solely to indicate this fact.

\section{References}

Asashima, M., H. Nakano, K. Shimada, K. Kinoshita, K. Ishii, H. Shibai, and N. Ueno. 1990. Mesodermal induction in early amphibian embryos by activin A (erythroid differentiation factor). Wilhelm Roux's Arch. Dev. Biol. 198: 330-335.

Bachvarova, R. and E.H. Davidson. 1966. Nuclear activation at the onset of amphibian gastrulation. J. Exp. Zool. 163: 285295.

Bailey, J.M. and N. Davidson. 1976. Methylmercury as a reversible denaturing agent for agarose gel electrophoresis. Anal. Biochem. 70: 75-85.

Blumberg, B., C.V.E. Wright, E.M. De Robertis, and K.W.Y. Cho. 1991. Organizer-specific homeobox genes in Xenopus laevis embryos. Science 253: 194-196.

Bopp, D., M. Burri, S. Baumgartner, G. Frigerio, and M. Noll. 1986. Conservation of a large protein domain in the segmentation gene bred paired and in functionally related genes of Drosophila. Cell 47: 1033-1040.

Cascio, S. and J.B. Gurdon. 1987. The initiation of new gene transcription during Xenopus gastrulation requires immediately preceding protein synthesis. Development 100: $297-$ 305.

Cho, K.W.Y. and E.M. De Robertis. 1990. Differential activation of Xenopus homeobox genes by mesoderm-inducing growth factors and retinoic acid. Genes $\Theta$ Dev. 4: 1910-1916.

Cho, K.W.Y., B. Blumberg, H. Steinbeisser, and E.M. De Robertis. 1991a. Molecular nature of Spemann's organizer: The role of the Xenopus homeobox gene Goosecoid. Cell 67: 1111-1120.

Cho, K.W.Y., E.A. Morita, C.V.E. Wright, and E.M. De Robertis. 1991 b. Overexpression of a homeodomain protein confers axis-forming activity to uncommitted Xenopus embryonic cells. Cell 65: 55-64.

Church, G.M. and W. Gilbert. 1984. Genomic sequencing. Proc. Natl. Acad. Sci. 81: 1991-1995.

De Robertis, E.M., G. Oliver, and C.V.E. Wright. 1989. Determination of axial polarity in the vertebrate embryo; homeodomain proteins and homeogenetic induction. Cell 57: 189-191.

Elinson, R.P. and K.R. Kao. 1989. The location of dorsal information in frog early development. Dev. Growth Differ. 31: 423-430.

Frei, E., R. Schuh, S. Baumgartner, M. Burri, M. Nou, G. Jürgens, E. Seiffert, U. Nauber, and H. Jäckle. 1988. Molecular characterization of Spalt, a homeotic gene required for head and tail development in the Drosophila embryo. EMBO J. 7: 197204.

Frohman, M.A., M. Boyle, and G.R. Martin. 1990. Isolation of the mouse Hox-1.9 gene; analysis of embryonic expression suggests that positional information along the anterior-posterior axis is specified by mesoderm. Development 110: $589-607$.

Gerhart, J., M. Danilchik, T. Doniach, S. Roberts, B. Rowning, and R. Stewart. 1989. Cortical rotation of Xenopus egg: Consequences for the anteroposterior pattern of embryonic dorsal development. Development (Suppl.) 107: 37-51.

Harland, M.R. 1991. In situ hybridization; an improved wholemount method for Xenopus embryos. Methods Cell Biol. (in press).

Hatta, K., C.B. Kimmel, R.K. Ho, and C. Walker. 1991. The cyclops mutation blocks specification of the floor plate of the zebrafish central nervous system. Nature 350: 338-341.

Hemmati-Brivanlou, A. and M.R. Harland. 1989. Expression of an engrailed related protein is induced in the anterior ectoderm of early Xenopus embryos. Development 106: 611617.

Hemmati-Brivanlou, A., D. Frank, M.E. Bolce, B.D. Brown, H.L. Sive, and R.M. Harland. 1990. Localization of specific mRNAs in Xenopus embryos by whole-mount in situ hybridization. Development 110: 325-330.

Herr, W., R.A. Sturm, R.G. Clerc, L.M. Corcoran, D. Baltimore, P.A. Sharp, H.A. Ingraham, M.G. Rosenfeld, M. Finney, G. 
Ruvkun, and H.R. Horwitz. 1988. The POU domain: A large conserved region in the mammalian pit-1, oct-1, oct-2, and Caenorhabditis elegans unc-86 gene products. Genes \& Dev. 2: 1513-1516.

Jamrich, M., T.D. Sargent, and I.B. Dawid. 1987. Cell-type-specific expression of epidermal cytokeratin genes during gastrulation of Xenopus laevis. Genes \& Dev. 1: 124-132.

Jürgens, G. 1988. Head and tail development of the Drosophila embryo involves Spalt, a novel homeotic gene. EMBO $/$. 7: 189-196.

Jürgens, G. and D. Weigel. 1988. Terminal versus segmental development in the Drosophila embryo: The role of the homeotic gene fork head. Wilhelm Roux's Arch. Dev. Biol. 197: 345-354.

Kessel, M. and P. Gruss. 1990. Murine developmental control genes. Science 249: 374-379.

Kimelman, D. and M. Kirschner. 1987. Synergistic induction of mesoderm by FGF and TGF-beta and the identification of an mRNA coding for FGF in the early Xenopus embryo. Cell 51: 869-877.

Kintner, C.R. and D.A. Melton. 1987. Expression of Xenopus N-CAM RNA in ectoderm is an early response to neural induction. Development 99: 311-325.

Lai, E., V.R. Prezioso, E. Smith, O. Litvin, R.H. Costa, and J.E. Darnell Jr. 1990. HNF-3A, A hepatocyte-enriched transcription factor of novel structure is regulated transcriptionally. Genes \& Dev. 4: 1427-1436.

Lai, E., V.R. Prezioso, W. Tao, W.S. Chen, and J.E. Darnell Jr. 1991. Hepatocyte nuclear factor $3 \alpha$ belongs to a gene family in mammals that is homologous to the Drosophila homeotic gene fork head. Genes \& Dev. 5: 416-427.

Mackem, S. and K.A. Mahon. 1991. Ghox 4.7: A chick homeobox gene expressed primarily in limb buds with limbtype differences in expression. Development 112: 791-806.

Mathews, L.S. and W.W. Vale. 1991. Expression cloning of an activin receptor, a predicted transmembrane serine kinase. Cell 65: 973-982.

Nambu, J.R., J.O. Lewis, K.A. Wharton, and S.T. Crews. 1991. The Drosophila single-minded gene encodes a helix-loophelix protein that acts as a master regulator of $\mathrm{CnS}$ midline development. Cell 67: 1157-1167.

Newport, J. and M. Kirschner. 1982. A major developmental transition in early Xenopus embryos. 1. Characterization and timing of cellular changes at the midblastula stage. Cell 30: 675-686.

Nieuwkoop, P.D. 1973. The "Organization center" of the amphibian embryo: Its origin, spatial organization, and morphogenetic action. Adv. Morphogenet. 10: 1-39.

Nieuwkoop, P.D. and I. Faber. 1967. Normal table of Xenopus laevis (Daudin). North-Holland, Amsterdam, The Netherlands.

Richter, K., H. Grunz, and I.B. Dawid. 1988. Gene expression in the embryonic nervous system of Xenopus laevis. Proc. Natl. Acad. Sci. 85: 8086-8090.

Ringold, G.M. 1979. Glucocorticoid regulation of mouse mammary tumor virus gene expression. Biochem. Biophys. Acta 560: 487-508.

Roberts, A.P., P. Kondaiah, F. Rosa, S. Watanabe, P. Good, D. Danielpour, N.S. Roche, M.L. Rebbert, I.B. Dawid, and M.B. Sporn. 1990. Mesoderm induction in Xenopus laevis distinguishes between the various TGF-beta isoforms. Growth Factors 3: 277-286.

Rosa, F.M. 1989. Mix 1, a homeobox mRNA inducible by mesoderm inducers, is expressed mostly in the presumptive endodermal cells of Xenopus embryos. Cell 57: 965-974.

Rosa, F. and I.B. Dawid. 1990. Molecular studies on mesoderm induction in Xenopus. In UCLA Symposia on Developmental Biology, pp. 163-174. Wiley-Liss, New York.

Rosa, F., A.B. Roberts, D. Danielpour, L.L. Dart, M.B. Sporn, and I.B. Dawid. 1988. Mesoderm induction in amphibians: The role of TGF-beta 2-like factors. Science 239: 783-785.

Rosenfeld, M.G. 1991. POU-domain transcription factors: Pouer-ful developmental regulators. Genes \& Dev. 5: 897-907.

Ruiz i Altaba, A. 1990. Neural expression of the Xenopus homeobox gene Xhox 3: Evidence for a patterning neural signal that spreads through the ectoderm. Development 108: 595604.

Ruiz i Altaba, A. and D.A. Melton. 1989. Interaction between peptide growth factors and homeobox genes in the establishment of antero-posterior polarity in frog embryos. Nature 341: 33-38.

Saiki, R.K., D.H. Gelfand, S. Stoffel, S.J. Scharf, R. Higuchi, G.T. Horn, K.B. Mullis, and H.A. Ehrlich. 1988. Primer-directed enzymatic amplification of DNA with a thermostable DNA polymerase. Science 239: 487-491.

Sargent, T.D. and I.B. Dawid. 1983. Differential gene expression in the gastrula of Xenopus laevis. Science 222: 135-139.

Sargent, T.D., M. Jamrich, and I.B. Dawid. 1986. Cell interactions and the control of gene activity during early development of Xenopus laevis. Dev. Biol. 114: 238-246.

Scott, M.P., J.W. Tamkun, and G.W. Hartzell. 1989. The structure and function of the homeodomain. BBA Rev. Cancer 9: $25-48$.

Slack, J.M.W., B.G. Darlington, J.K. Heath, and S.F. Godsave. 1987. Mesoderm induction in early Xenopus embryos by heparin-binding growth factors. Nature 326: 197-200.

Smith, J.C. 1989. Mesoderm induction and mesoderm-inducing factors in early amphibian development. Development 105: 665-677.

Smith, J.C., B.M.J. Price, K. Van Nimmen, and D. Huylebroeck. 1990. Identification of a potent Xenopus mesoderm inducing factor as a homologue of activin A. Nature 345: 729-731.

Sokol, S., G.G. Wong, and D.A. Melton. 1990. A mouse macrophage factor induces head structures and organizes a body axis in Xenopus. Science 249: 561-565.

Spemann, H. and H. Mangold. 1924. Ueber Induktion von Embryonalanlagen durch Implantation artfremder Organisatoren. Wilhelm Roux's Arch. Entwicklungsmech. Org. 100: 599-638.

Taira, M., M. Jamrich, P.J. Good, and I.B. Dawid. 1992. The LIM domain-containing homeobox gene Xlim-1 is expressed specifically in the organizer region of Xenopus gastrula embryos. Genes \& Dev. 6: 356-366.

Thomsen, G., T. Woolf, M. Whitman, S. Sokol, J. Vaughan, W. Vale, and D.A. Melton. 1990. Activins are expressed early in Xenopus embryogenesis and can induce axial mesoderm and anterior structures. Cell 63: 485-493.

Walther, C., J.L. Guenet, D. Simon, U. Deutsch, B. Jostes, M.D. Goulding, D. Plachou, R. Balling, and P. Gruss. 1991. Pax: A murine multigene family of paired box-containing genes. Genomics 11: 424-434.

Weigel, D. and H. Jäckle. 1990. The fork head domain: A novel DNA binding motif of eukaryotic transcription factors? Cell 63: 455-456.

Weigel, D., G. Jürgens, F. Kuettner, E. Seifert, and H. Jäckle. 1989. The homeotic gene fork head encodes a nuclear protein and is expressed in the terminal regions of the Drosophila embryo. Cell 57: 645-658.

Wright, C.V.E., K.W.Y. Cho, G. Oliver, and E.M. DeRobertis. 1989. Vertebrate homeodomain proteins: Families of regionspecific transcription factors. Trends Biochem. Sci. 14: 5256. 


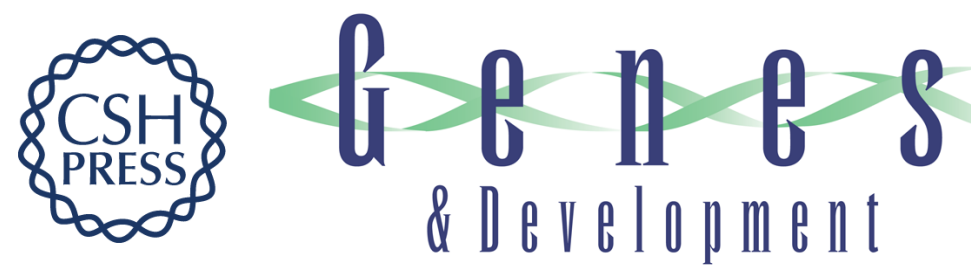

\section{A novel, activin-inducible, blastopore lip-specific gene of Xenopus laevis contains a fork head DNA-binding domain.}

M L Dirksen and M Jamrich

Genes Dev. 1992, 6:

Access the most recent version at doi:10.1101/gad.6.4.599

References This article cites 55 articles, 24 of which can be accessed free at:

http://genesdev.cshlp.org/content/6/4/599.full.html\#ref-list-1

License

Email Alerting

Service

Receive free email alerts when new articles cite this article - sign up in the box at the top right corner of the article or click here.

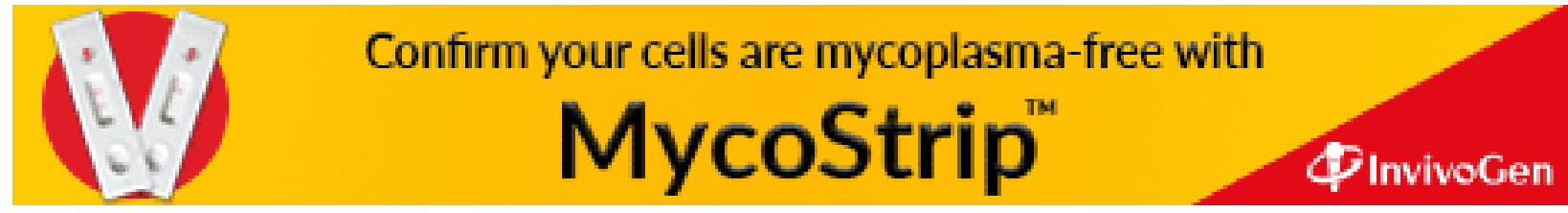

